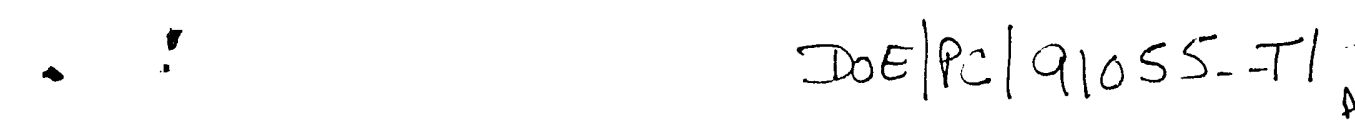

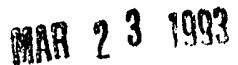

\title{
THE ROLE OF THE RESID SOLVENT IN CO-PROCESSING WITH FINELY DIVIDED CATALYSTS
}

$\mathrm{DOE} / \mathrm{PC} / 91055--\mathrm{T} 1$

DE93 012469
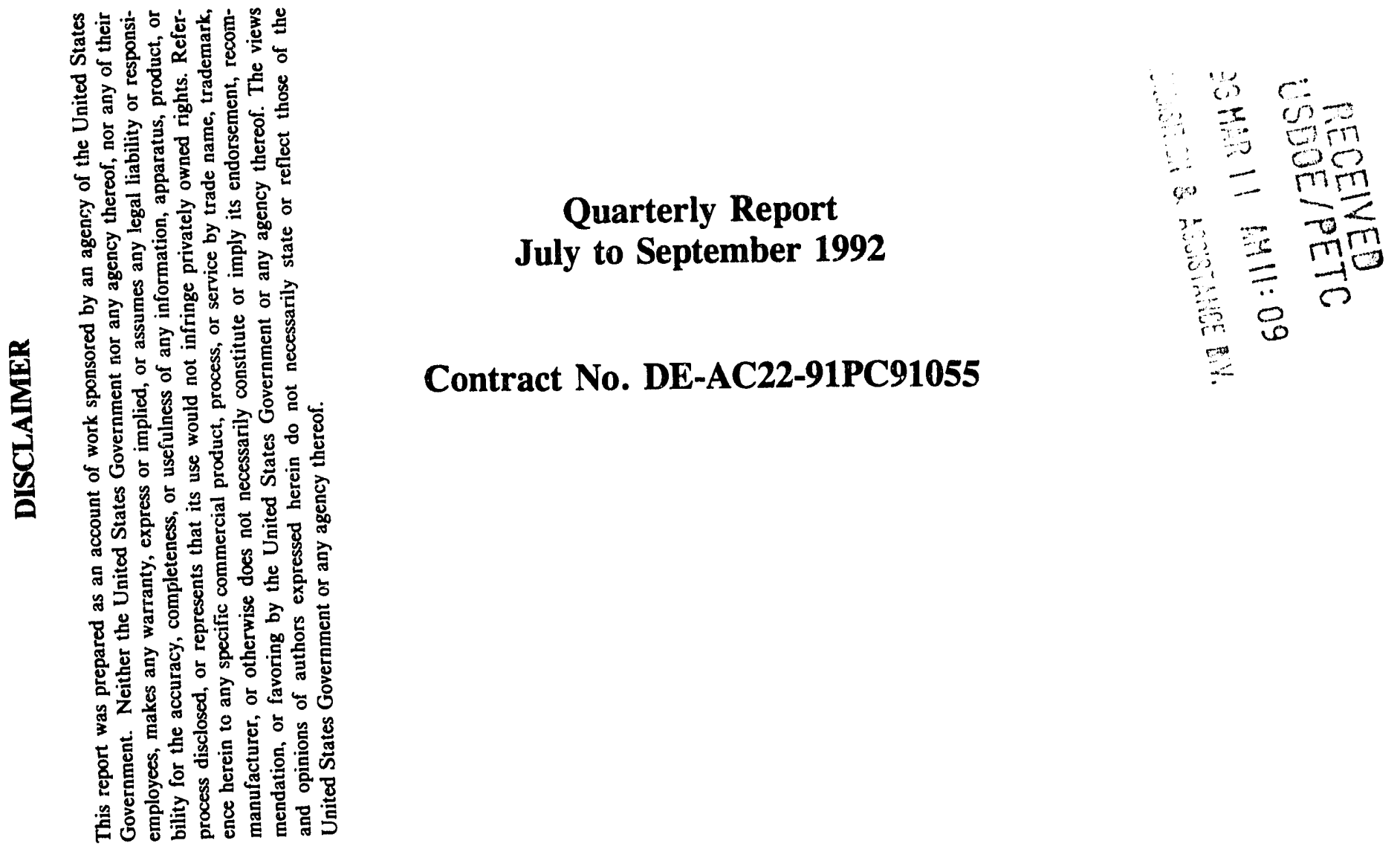

Christine W. Curtis

Chemical Engineering Department

Auburn University, Alabama 36849 


\section{Acknowledgements}

The experimental research of Mr. Jing Shen is gratefully acknowledged. The technical assistance of Mr. J. Aderholdt and Mr. F. Bowers is also appreciated. 


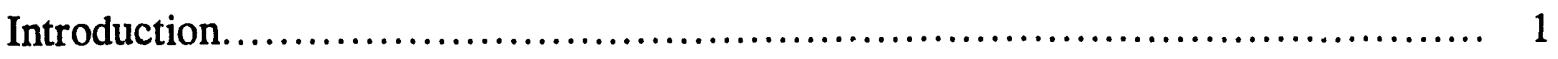

Literature Review...........................................................

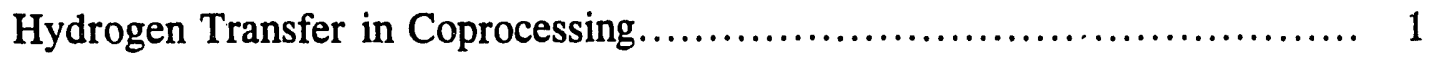

Binary Solvent Systems........................................ 2

Single Solvent Systems........................................ 5

Implications of the Literature on Hydrogen Transfer Among Different Molecular Species............................................. 14

Hydrogen Donation in Coprocessing................................... 15

Hydrogen Donation Between Cycloalkanes and Coal.................. 15

Effects of Phenolics on Hydrogen Transfer........................... 19

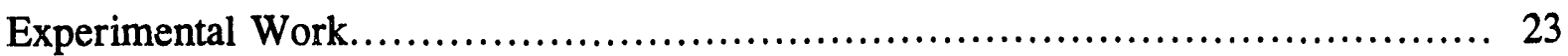

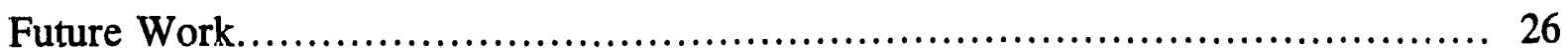




\section{INTRODUCTION}

The overall objective of this project is to evaluate the role of the resid in co-processing. The primary purpose of the initial work was to establish under thermal and catalytic reaction conditions whether hydrogen transfer occurred between cycloalkane type structures that are present in resids and aromatics that are present in coal and liquefied coal. The idea being explored was to determine if hydrogen could be transferred from the cycloalkane to the aromatic in a hydrogen atmosphere. The reason that the hydrogen atmosphere is important is because a hydrogen atmosphere is always present in co-processing. In order to determine if the reactions probably occur during co-processing, the conditions need to simulate those of co-processing as much as possible. Hence, catalytic as well as thermal reactions need to be performed because it is most likely that co-processing will be performed under catalytic conditions.

\section{LITERATURE REVIEW}

\section{Hydrogen Transfer in Coprocessing}

In order to understand the role of resid in co-processing, it is necessary to know if hydrogen transfer occurs from the resid to coal during the coprocessing reaction. Hydrogen transfer from hydroaromatic has been shown to effective in converting coal and maintaining the product slate in direct coal liquefaction (Chiba et al., 1987a,b; Obara et al., 1983; Clarke et al., 1990). Other studies have shown that under certain conditions, cycloalkanes in petroleum resid donate hydrogen (Clarke et al., 1984; Tagaya et al., 1988). Since cycloalkanes are rich in hydrogen, they provide a valuable source of hydrogen in the co-processing system. The objective of this research is to determine the conditions under which the hydrogen present in cycloalkanes becomes available to coal. 
Binary Solvent Systems. Hydrogen-rich compounds like cycloalkanes are considered to be fairly poor solvents for coal whereas hydroaromatic compounds like dihydroanthracene (DHA) (Bedell and Curtis, 1993) and dihydrophenanthrene (DHPH) (Song et al., 1988) are considered to be good hydrogen donors. Aromatics like pyrene iend to be good solvents for coal and participate in hydrogen shuttling (Derbyshire and Whitehurst, 1981).

Because it is commonly accepted that hydrogen rich compounds, such as cycloalkanes, are usually poor coal solvents and that many non-donor polynuclear aromatics are good coal solvents and demonstrate a hydrogen shuttling ability, the literature was examined to find if a possible synergism might occur when a binary solvent system, such as one made up of a cycloalkane and an aromatic, was used in the liquefaction of coal.

Clarke et al. (1984) performed coal extractions in the absence of gaseous hydrogen using cycloalkanes, aromatics, and cycloalkane/aromatic mixtures as solvents. The cycloalkanes: decalin, perhydrophenanthrene, and perhydropyrene, the aromatics: naphthalene, phenanthrene and pyrene, and cycloalkane/aromatic mixtures of the above compounds were determined to be thermally stable at an extraction temperature of $430^{\circ} \mathrm{C}$ with a residence time of 60 minutes. Certain cycloalkane/aromatic mixtures resulted in higher extraction yields than with the cycloalkanes or aromatics alone. The authors concluded that lower concentrations of cycloalkanes and higher concentrations of their corresponding hydroaromatic and aromatic compounds after extraction with coal were indicative that hydrogen was transferred from the cycloalkanes to the coal radicals. It was estimated that approximately $1 \%$ hydrogen was donated, based on differences in composition between the starting mixtures and recovered solvents, for 
the cycloalkane/aromatic mixtures of perhydrophenanthrene/phenanthrene, perhydrophenanthrene/pyrene, and perhydropyrene/phenanthrene.

Tagaya et al. (1988) used indene with decalin, decane, and tetracosane to study solventsolvent interactions in the liquefaction of two bituminous coals, Taiheiyo and Wandoan, and one brown coal, Yallourn, in a nitrogen atmosphere. Each solvent's ability to donate hydrogen was evaluated by heating it with anthracene to $400^{\circ} \mathrm{C}$ and determining the amount of dihydroanthracene produced. A synergistic effect was observed in the decalin/indene solvent system. There was some indication that decalin/indene interactions were present and it was thought by the authors that this may have an accelerating effect on the hydrogen transfer reaction. When mixtures of decane/indene and tetracosane/indene were used as the coal solvent, there was a detrimental effect on the coal conversion indicating that saturated chain compounds hindered coal liquefaction.

It was found that indene oligomerized at the reaction conditions used and that the conversion of Taiheiyo coal was higher using the benzene soluble indene oligomer than using indene alone. This indicated that the indene oligomer is a hydrogen donor. Indene itself does not appear to have donable hydrogen and, therefore, it was thought that indene must oligomerize during the initial step.

Tagaya and his coworkers (1988) proposed a mechanism by which the indene oligomerizes in the heat-up period at $250-300^{\circ} \mathrm{C}$ with the oligomer donating hydrogen to the coal. The dehydrogenated form of the oligomer would then accept hydrogen from decalin, which is converted to tetralin, to enable the oligomer to donate hydrogen to the coal again. In this way, the indene oligomer acts as a hydrogen shuttler. 
Chiba et al. (1987) investigated the interactions between the components of a binary solvent, tetralin plus a polynuclear aromatic compound, and their solvent donor ability in the liquefaction of Yallourn coal in both a nitrogen and a hydrogen atmosphere. Naphthalene, 1methylnaphthalene, fluorene, and phenanthrene, were each used as a cosolvent with tetralin since they were representative of polynuclear aromatics found in the recycle solvent. Mixtures of fluorene or phenanthrene with tetralin yielded greater coal conversions than mixtures of naphthalene or 1-methylnaphthalene with tetralin, regardless of the atmosphere or reaction time. Although fluorene was found to be a more effective cosolvent than phenanthrene, both demonstrated synergism with the tetralin.

The amount of transferred hydrogen from tetralin to coal was measured from the amount of naphthalene present in the recovered solvent. In mixtures of fluorene and tetralin a large amount of hydrogen was transferred, indicating the presence of interactions between the fluorene and tetralin. The amount of transferred hydrogen using tetralin/fluorene mixtures was greater in a nitrogen atmosphere than in a hydrogen atmosphere.

The hydrogen donor ability of the solvent was evaluated by measuring the amount of anthracene that was converted to dihydroanthracene in a nitrogen atmosphere and was found to be as follows: tetralin $>>$ fluorene $>1$-methylnaphthalene $>$ phenanthrene. The hydrogen donor ability in $25 / 75$ and 50/50 mixtures of tetralin and fluorene was higher than the other binary solvents.

The participation of a hydrogen molecule in coal conversion was suggested by the fact that the conversion to tetrahydrofuran solubles was somewhat greater in a hydrogen atmosphere than in a nitrogen atmosphere, when only fluorene was used as a solvent. However, in 25/75 
mixtures of tetralin/fluorene and tetralin/1-methylnaphthalene, the difference in conversion to tetrahydrofuran soluhles in a hydrogen and nitrogen atmosphere was only $16 \%$ and $3 \%$, respectively, indicating that the molecular hydrogen only plays a small role in hydrogen donation.

The authors suggested the following: 1) hydrogen transfer from tetralin to coal is accelerated by interacions between the tetralin and a shuttler, such as fluorene, 2) the physical affinity of fluorene and phenanthrene with Yallourn coal is large and allows for the shuttling of hydrogen to coal. and 3) " nuorene does donate hydrogen to coal."

Single Solvent Systems. Studies have been made that examine the solvent and hydrogen transfer abilities of a compound at different levels of saturation. Decalin and its less saturated counterparts were studied in liquefaction reactions with model coal compounds.

Ouchi and Makabe (1988) investigated the main pathway for hydrogen donation to a model sample in the presence of a hydrogen donor, a catalyst, and a hydrogen atmosphere. Dibenzyl and benzyl phenyl ether were each reacted with naphthalene, tetralin, and decalin in hydrogen and nitrogen atmosphere at 250 and $400^{\circ} \mathrm{C}$, using a stabilized nickel catalyst. The results for the dibenzyl sample were similar at the two different temperatures. There was no donor activity for decalin or tetralin in a nitrogen atmosphere with a catalyst or in a hydrogen atmosphere without a catalyst. The reactions performed with the dibenzyl in a hydrogen atmosphere with a catalyst, resulted in a $100 \%$ conversion of the dibenzyl in the decalin, tetralin and naphthalene solvents. The dibenzyl was converted to its saturated analogues with no splitting of the central $\mathrm{C}-\mathrm{C}$ bond, indicating that hydrogen was donated mainly from molecular hydrogen and not from the donor solvents. 
The dibenzyl conversions by the solvents were as follows:

$$
\text { decalin }>\text { tetralin }>\text { naphthalene. }
$$

The solvent conversion was as follows:

$$
\text { decalin }<\text { tetralin }<\text { naphthalene. }
$$

According to Ouchi, this tendency of the solvents might depend on the adsorption of the solvent onto the catalyst surface. Naphthalene is adsorbed strongly onto the catalyst surface, whereas decalin is adsorbed weakly. This naphthalene adsorption makes less surface available and inhibits sample conversion. The opposite happens for the decalin and the above conversions are the result.

Benzyl phenyl ether was used as the model coal compound in the second part of Ouchi's experiment to observe if a sample with a weak bond, such as the $\mathrm{C}-\mathrm{O}$ bond, would allow for the production of radicals and acceptance of hydrogen from the donor solvent. At $250^{\circ} \mathrm{C}$ in a nitrogen atmosphere with a catalyst and in a hydrogen atmosphere without a catalyst the results were much the same as with the dibenzyl. There was negligible conversion for both sample and solvent. In a hydrogen atmosphere with a catalyst, there was $100 \%$ conversion of the benzyl phenyl ether using either decalin or tetralin as the solvent and $84 \%$ using naphthalene. The central $\mathrm{C}-\mathrm{O}$ bond was split and the main products were methylcyclohexane, toluene, and cyclohexanol. The donor solvent was not effective and the reaction occurred by the direct hydrogenation of the gaseous hydrogen onto the catalyst surface. The sample conversion followed the same trend as for the dibenzyl: decalin $>$ tetralin $>$ naphthalene. The solvent conversion trend was opposite that of the dibenzyl and was the same as the sample conversion. 
The results are more complex for the benzyl phenyl ether reâction at $400^{\circ} \mathrm{C}$. Fairly high conversion occurred in nitrogen atmosphere with or without a catalyst and in hydrogen atmosphere without a catalyst. A gas chromatogram contained evidence of a wide variety of products, many rearranged and polymerized compounds, and it was roughly estimated that even in tetralin, no more than half of the hydrogen was donated from the donor solvent. The rest of the necessary hydrogen came from the hydrogen liberated by the condensation products. Benzyl phenyl ether thermally decomposes easily and produces a large number of radicals that require a large amount of hydrogen to be quenched, and even tetralin can not meet the requirement. As a result, radicals condense with the solvent or polymerize each other and the coke fraction is increased. Low rank coals, which may have many weak bonds, exhibit this kind of behavior and require large amounts of available hydrogen.

When benzyl phenyl ether was reacted at $400^{\circ} \mathrm{C}$ in a hydrogen atmosphere with a catalyst, the amount of highly hydrogenated compounds increased, indicating that the radicals were being supplied with enough hydrogen. The hydrogen was still being supplied from the gaseous hydrogen. Conversion of the sample by the solvent was: decalin $>$ tetralin $>$ naphthalene and the conversion of the solvent was the reverse of this.

The authors concluded that at each of the reaction conditions, with each of the solvents, that the main hydrogenation pathway of both dibenzyl and benzyl phenyl ether was direct hydrogenation by gaseous hydrogen on the catalyst surface.

Obara et al. (1983) investigated the hydrogen transfer reaction by evaluating the hydrogen donor and acceptor ability of model compounds and by relating this to their chemical structure. 
The hydrogen used were decalin, tetralin, 1,2-dihydronaphthalene, and 1,4-dihydronaphthalene, and the hydrogen acceptors used were anthracene, phenanthrene, and acenaphthylene.

The hydrogen donor ability of the donor compounds was based on the amount of naphthalene produced following heat treatment and was determined by gas chromatography. The ability to donate hydrogen is as follows:

$$
\text { decalın }<\text { tetralin }<1 \text {,2-dihydronaphthalene }<<1 \text {,4-dihydronaphthalene. }
$$

By using ' $H$ NMR to monitor the amounts of 9,10-dihydroanthracene being produced from anthracene. and acenaphthene being produced from acenaphthylene, the ability of the donor solvents to transfer hydrugen is as follows:

$$
\text { 1.4-dihydronaphthalene }>\text { 1,2-dihydronaphthalene }>\text { tetralin. }
$$

A comparison of the peak intensities of the NMR spectra of the anthracene and the acenaphthylene indicated that the latter may be a better acceptor for hydrogen transfer. No hydrogen transfer was observed for phenanthrene. The ease of hydrogenation of the acceptors is as follows: phenanthrene $<$ anthracene $<$ acenaphthylene.

The INDO (intermediate neglect of differential overlap) method was used to calculate the difference in bonding energies, $\mathrm{E}$, of the hydroaromatic compounds and their radicals. It was assumed that the smaller the value of $\mathrm{E}$, the more easily a compound would form a radical, and thus $\mathrm{E}$ represents the bond dissociation energy of the hydrogen at a given position. The calculated values of $E$ were found to be the largest for decalin and the smallest for 1,4dihydronaphthalene, with 1,2-dihydronaphthalene having an intermediate value, which is what was expected and is in agreement with results reported elsewhere. 
Schulten and Marzec (1987) used field ionization mass spectrometry (FIMS) to compare the spectra of coal and hydrogenated coal in order to distinguish between the hydrogenation products and other materials released from the coal. A low rank bituminous coal was hydrogenated with decalin in the temperature range from 340 to $450^{\circ} \mathrm{C}$ and aliquots at different temperatures were analyzed by gas chromatography, which revealed that coal radicals were thermally generated between 390 and $410^{\circ} \mathrm{C}$.

The coal studied using FIMS was reacted at $440^{\circ} \mathrm{C}$ with decalin. An integrated spectrum of the unreacted coal showed molecular ions from 108 to 800 daltons, and a spectrum of the reacted coal showed molecular ions from 108 to 550 daltons. By comparing the spectra of selected ions of a particular homologous series, it was seen that there was a higher abundance of ions in a lower mass range and a lower abundance of ions in the higher mass range for the reacted coal. The authors postulated that this indicated that thermal cleavage of coal occurred, followed by hydrogen capping from the hydrogen donor. The fact that the substances belonged to seven different homologous series indicated that weak $\mathrm{C}-\mathrm{O}$ and $\mathrm{C}-\mathrm{C}$ bonds were attached to a great variety of structural moieties.

Process Solvent Systems. The solvent and hydrogen transfer ability of actual process solvents has been studied using both coal and model acceptor compounds.

Rincon and Angulo (1986) examined the effects of using a petroleum heavy oil and an anthracene oil, both separately and in a mixture, as a solvent in the liquefaction of Cerrejon coal. Petroleum heavy oil is rich in hydrogen but is a poor coal solvent, whereas anthracene oil is a good coal solvent but not a good source of hydrogen. A synergistic effect occurred when a petroleum heavy oil/anth acene oil mixture was used as the solvent. In addition to yielding a 
higher conversion than attainable using either of the oils alone, the mixture also had a lower maximum conversion temperature.

There is an indication that cycloalkanes in the petroleum heavy oil may release hydrogen upon heating. NMR spectroscopy revealed that the concentration of the aromatic structure increased when petroleum heavy oil was heated. When anthracene was used as the coal model compound and heated with the petroleum heavy oil, NMR spectroscopy indicated that $9,10-$ dihydroanthracene was formed. NMR spectroscopy also indicated that the anthracene oil consists largely of aromatic structures.

Rincon and Angulo (1986) proposed that both direct and indirect hydrogen transfer mechanisms are occurring simultaneously and are indeed the reason for the synergistic effect that occurred when a petroleum heavy oil/anthracene oil mixture was used as a coal solvent. The direct hydrogen transfer is believed to occur when the anthracene oil acts as a solvent for the coal fractions and increases the interaction of the coal and the petroleum heavy oil. The free radicals from the coal are quenched by hydrogen released from the petroleum heavy oil. Indirect hydrogen transfer is thought to occur when hydroaromatic species are formed in the anthracene oil and result in hydrogen transfer to the coal fragments.

Kuhlmann et al. (1985) nıeasured the rate of hydrogen donation from various hydroaromatic species present in hydrogenated creosote oil during the liquefaction of Illinois No. 6 bituminous coal, in order to rank the reactivities of various hydrogen donors. Integrated gas liquid chromatography was used to approximate the amounts of various hydroaromatic species in the hydrogenated creosote oil. There was no effective change in the concentration of these species in the absence of coal under reaction conditions for short times. 
The rate of disappearance of the hydroaromatics under consideration was based on a pseudo first-order reaction model since true reaction kinetics were not known. Table 1 shows the rates of hydrogen donation of different species at different hydrogen reaction pressures. The authors observed that coal-derived radicals exhibit a selectivity in hydrogen abstraction but will abstract hydrogen from less reactive donors if the more reactive ones are not present. It was observed that the low donor activity of tetralin and other six-membered hydroaromatic derivatives may have been a result of the reaction conditions which may have led to vaporizing or isomerizing a portion of these compounds. The authors concluded that if the composition of the recycle solvent could be hydrotreated in such a way as to maximize better hydrogen donors and minimize the poor hydrogen donors, less molecular hydrogen would be needed resulting in a more economically feasible coal liquefaction process.

Later and Camaioni (1985) measured the hydrogen donating properties of two process solvents by investigating their ability to initiate the reduction reaction of fluorenone to fluorene at $400^{\circ} \mathrm{C}$ and to transfer hydrogen to the radicals. One of the process solvents used was a Solvent Refined Coal (SRC)-I process solvent, while the other was a recycle pasting solvent from the Wilsonville, AL integrated two-stage liquefaction (ITSL) process. These two solvents were divided into four chemical classes: (1) aliphatic hydrocarbons, (2) neutral polycyclic aromatic hydrocarbons (PAH), (3) nitrogen-containing polycyclic aromatic compounds (NPAC), and (4) hydroxylated PAH (HPAH). 
Table 1. Relative Rates of Hydrogen Donation During Coal Liquefaction

Reactions pressure $\mathrm{MPa} \mathrm{H}_{2}$ (cold)

4.13

9.64

Donor

$1,2,3,10 \mathrm{~b}-$ Tetrahydrofluoranthene

4,5-Dihydropyrene

9,10-Dihydrophenanthrene

Decahydrofluoranthene

1,2,3,3a,4,5-Hexahydropyrene

$1,2,3,6,7,8$-Hexahydropyrene

9,10-Dihydroanthracere

$1,2,3,4,5,6,7,8$-Octahy drophenanthrene

$2 \mathrm{a}, 3,4,5$-Tetrahydroacenaphthene

Tetralin

Methyltetralins

1,2,3,4-Tetrahydrophenanthrene

$1,2,3,4,5,6,7,8$-Octahydroanthracene

a - No hydrogen donation observed

$\begin{array}{rr}20 & 19 \\ 7 & 8 \\ 5 & 9 \\ 4 & 9 \\ 4 & 7 \\ 4 & 5 \\ 2 & 2 \\ 1 & 1 \\ \mathrm{a} & \mathrm{a} \\ \mathrm{a} & \mathrm{a} \\ \mathrm{a} & \mathrm{a} \\ \mathrm{a} & \mathrm{a} \\ \mathrm{a} & \mathrm{a}\end{array}$

The conversion yields for the reduction of fluorenone to fluorene by the two solvents, both in their crude form and in their different fractions, is shown in Table 2 . The high recoveries resulting from the crude form of the solvents and the aliphatic hydrocarbon and neutral PAH fractions indicated that little adduction of intermediate radicals had occurred. The more polar constituents exhibited lower recoveries indicating that adduction of intermediate radicals had occurred with the NPAC and HPAH fractions. 


\section{Table 2. Conversion of Fluorenone to Fluorene by Two Coal Liquids and Their Chemical Fractions}

Sample Fraction $\quad \%$ Conversion $\%$ Recovery

SRC-I Process

Solvent:

Crude

A1

A2

A3

A4

ITSL Recycle

Paste Solvent

Crude

A1

A2

A3

A4
38

1

7

45

43

88

9

44

65

57

0
91

89

95

78

81

Fluorenone Only

$---$

85

a) Key. Al = aliphatic hydrocarbons; A2 - neutral PAH; A3 = NPAC; A4 = HPAH

b) $\%$ Conversion is quantity of fluorene in moles versus the initial fluorenone quantity normalized to $5 \mathrm{mg}$ sample.

c) $\%$ Recovery is the sum of both fluorene and fluorenone as compared with the initial fluorenone quantity.

The ITSL solvent, which contained high boiling, high molecular weight constituents, had a higher conversion (88\%), than the SRC-I solvent (38\%), which contained intermediate boiling point and molecular weight constituents. The ITSL solvent may have yielded a better conversion than the SRC-I solvent because it contained higher levels of aliphatic hydrocarbons, lower levels of heteroatomic PAH compounds, and certain hydrogen donating species, such as dihydropyrene. 
The NPAC fraction produced the highest conversions, followed closely by the HPAH, and the PAH, and finally the aliphatic hydrocarbon fraction. This indicates that the more polar fractions of the solvent participate in the reduction initiation step and in hydrogen transfer. The higher levels of NPAC in the ITSL solvent may have been another reason this solvent had higher conversions than the SRC-I solvent.

The authors demonstrated how the reduction of fluorenone to fluorene could be used to compare very different process solvents. For the particular solvents used in this study, it appeared to be the more polar constituents were the most effective radical initiators and hydrogen donors.

Implications of the Literature on Hydrogen Transfer Among Different Molecular Species.

Several different ideas on how hydrogen is transferred in coal liquefaction appear in this literature search. Studies made by Chiba et al. (1987) indicated that when certain solvent combinations are used, molecular hydrogen plays only a small role in donating hydrogen. On the other hand, Ouchi and Makabe (1988) felt that their studies revealed molecular hydrogen to be a major source of hydrogenation.

Of particular interest are those points made concerning the transfer of hydrogen from cycloalkanes to coal. Clarke et al. (1984) and Tagaya et al. (1988) suggested that cycloalkanes could contribute to hydrogen donation, while Obara et al. (1983) felt that decalin was a very poor hydrogen donor compound. Rincon and Angulo (1986) concluded that NMR spectra revealed cycloalkanes in a petroleum heavy oil released hydrogen upon heating, and Schulten and Marzec (1988) felt that FIMS spectra revealed hydrogen donation from decalin to coal. 


\section{HYDROGEN DONATION IN COPROCESSING}

Hydrogen Donation between Cycloalkanes and Coal. Clarke et al. (1984) examined the reactivity of cycloalkanes in the extraction of bituminous coal at $430^{\circ} \mathrm{C}$ in an inert atmosphere. Many of the cycloalkanes and aromatic systems used in this work were reacted alone at reaction conditions to test their thermal reactivity. Then they were reacted as single solvents in the presence of coal. The product activity data which were obtained from combined reactions of cycloalkanes with polynuclear aromatics of three or more rings indicated a participation of the cycloalkanes in hydrogen donation reactions. The authors (Clarke et al., 1984) claimed that cycloalkane/aromatic mixtures containing decalin/phenanthrene and decalin/pyrene yielded much higher coal extraction yields than either the cycloalkane or aromatic alone. The products obtained from the reactions showed that the cycloalkanes were converted to their hydroaromatic and aromatic analogues and, hence, some hydrogen was released from the cycloalkane. It is unclear at this point whether these product molecules were totally derived from the solvent or if the reacted coal was a contributing source. The authors postulated that in presence of coal derived radicals and polynuclear aromatic compounds, cycloalkanes served as hydrogen donating species. This work has strong implications for coprocessing, suggesting that under a favorable set of reaction conditions and environment, possible hydrogen transfer may occur between naphthenes present in petroleum solvents and hydrogen accepting components of coal and residuum.

Hydrogen transfer among model compounds was also studied by Ouchi and Makabe (1988). The compounds, biphenyl and benzyl phenyl ether, were reacted together in the presence of naphthalene, tetralin and decalin in both hydrogen and nitrogen atmospheres at temperatures 
of 250 to $400^{\circ} \mathrm{C}$. Stabilized Ni was used as the catalyst. The primary reaction observed was direct hydrogenation of the species by $\mathrm{H}(\mathrm{g})$ on the catalyst surface.

In a thermodynamic study by Gagarin et al. (1979), the transfer of hydrogen in polynuclear systems was studied. The system consisted of anthracene as a hydrogen acceptor and tetralin as a hydrogen donor. Thermodynamic properties were evaluated from additivity. The key point pertinent to this review was that an excess of saturation of donor molecules hindered hydrogen transfer to aromatic systems. The calculated results agreed with liquefaction data as well as with other researchers (Curtis et al. 1981).

Schulten and Marzec (1987) examined the production of relatively low molecular weight products, 108 to 348 , during the hydroliquefaction of low rank bituminous coals with decalin. The products formed belonged to seven different homologous series indicating that the weak $\mathrm{C}-\mathrm{O}$ and C-C bonds in coal are composed of a variety of structures. The authors invoked the radical capping mechanism to explain the hydrogen donation of decalin.

Lang and coworkers (1984) examined the hydroliquefaction of coal under two conditions: (1) $400^{\circ} \mathrm{C}$ and $200 \mathrm{MPa}$ with $1 \%\left(\mathrm{NH}_{4}\right)_{2} \mathrm{MoO}_{4}$ and (2) $400^{\circ} \mathrm{C}$ and $200 \mathrm{MPa}$ with decalin and $\mathrm{CoMo} / \mathrm{Al}_{2} \mathrm{O}_{3}$ catalyst. Both of these conditions gave conversions of approximately $40 \%$; however, the products achieved were different since hydroliquefaction with decalin gave coal liquids containing -2 times less aromatic hydrocarbons than without the hydrogen donor.

Pajak and Brower (1987) have examined the mechanism of hydrogen transfer from decalin to coal. They evaluated the molar activation volume $\Delta \mathrm{V}$ and the H/D kinetic isotope effect where $\Delta \mathrm{V}$ for decalin at $400^{\circ} \mathrm{C}$ is $-70 \pm 5 \mathrm{~cm}^{3} / \mathrm{mol}$. They suggested a mechanism in which ionization of decalin accompanies or precedes the formation of the transition state. They do not 
believe that the rate is determined by the homolysis of the coal molecule. Other confirming evidence was that the H/D kinetic isotope effect for the coal-decalin reaction was $2.3 \pm 0.2$. In addition, experiments were performed with decalin in which the pressure effect and isotopic substitution effect on the rate of model reactions were also examined. On the basis of the $\Delta \mathrm{V}$ of $-55 \mathrm{~cm}^{3} / \mathrm{mol}$ and kinetic isotope effect being $2.1 \pm 0.2$ for the anthracene - decalin reaction, it appeared that this reaction proceeded in a fashion similar to the coal-decalin reaction.

Tagaya and coworkers (1988) have examined binary solvent systems comprised of a hydrogen donor, tetralin, and nondonor solvents to evaluate their mutual interaction during coal liquefaction and their ability to transfer hydrogen to anthracene. When combined with tetralin, the nondonor solvents fluorene, phenanthrene, indene and sulfur accelerated liquefaction; however, the pairing of n-paraffins or 1-olefins with tetralin or indene retarded liquefaction. The hydrogen donor measurement to anthracene was reflective, though lower, than that actually observed in coal liquefaction systems.

In a recent patent application, Rudnick (1986a) examined a hydrogenation process where hydrogen was transferred from a hydrogen donor selected from greater than $\mathrm{C}_{4}$ alkyl aliphatics and aromatics in shale oil to a hydrogen acceptor, benzophenone. A sulfur containing compound (thiophenol) or a $\mathrm{C}_{2}-\mathrm{C}_{12}$ mercaptan was used as a catalyst. Hydrogen was transferred from the shale oil to benzophenone under the conditions of $454^{\circ} \mathrm{C}$ for 2.5 minutes. In a related patent application, Rudnick (1986b) evaluated the conversion of alicyclic compounds into their corresponding aromatics using a sulfur containing species such as thiol or thiophenol as a catalyst. The system evaluated included perhydropyrene as the hydrogen donor and bezophenone 
as the acceptor with $0.51 \mathrm{wt} \%$ thiophenol as the catalyst. A conversion of $94.7 \%$ benzophenone to diphenylmethane at $440^{\circ} \mathrm{C}$ was obtained; pyrene was observed as a product.

Interactions between hydrogen donor and aromatic systems for the liquefaction of Yallourn coal have been investigated by Chiba et al. (1987a). Hydrogen transfer from tetralin to each was promoted by the addition of the aromatic species fluorene or phenanthrene as manifested by increased coal conversion. The promotional effect was not observed with mixtures of tetralin with either 1-methylnaphthalene or naphthalene. Anthracene as an acceptor was used to evaluate the donor ability of the different mixtures. The hydrogen donor abilities of the different mixtures were ranked according to fluorene-tetralin $>1$-methylnaphthalene $=$ tetralin $>$ naphthalene-tetralin. Coal conversions exhibited by Yallourn coal agreed with the hydrogen donor ranking exhibited by anthracene.

Hydrogen transfer reaction may be enhanced by the presence of additional compounds as demonstrated by a study by Chiba et al. (1987b). Benzophenone and dibenzyl ether were used as hydrogen acceptors. Hydrogen transfer from tetralin was accelerated by the presence of the following compounds in the order: anthracene $>$ fluorene $>$ pyrene - triphenylmethane $>$ phenanthrene $>$ 1-methylnaphthalene.

In some earlier work, Clarke et al. (1983) examined the distrition of donable hydrogen in hydrogenated anthracene oil and found that hydrogen transfer proceeded more readily in high boiling polynuclear solvents than in lower boiling single ring aromatic solvents. The amount of hydrogen transfer observed was determined by evaluating hydrogen transfer rates and coal dissolution rates in different hydrogenated oil fractions. The addition of pyrene to the lowest 
boiling fraction $<275^{\circ}$ improved both hydrogen transfer and coal dissolution by participating in and promoting hydrogen transfer reactions.

Coal liquefactıon was examined in an indene-nondonor mixture solvent by Tagaya et al. (1988). Three different coals, two bituminous and one brown, were liquefied in pairs of solvents: indene-decalın. indene-decane and indene-tetracosane. When compared to the results of the reactions of the individual components on coal liquefaction, the indene-decalin solvent mixtures yielded conversıons which were 10 to $40 \%$ higher. In addition, a synergistic effect on the production of dihy droanthracene from anthracene was also observed. The other two mixtures were detrimental to liquefaction. Hence, the indene oligomer most likely exhibited the synergistic effect by ahstracting hydrogen from decalin. Hence, the role of the indene as a hydrogen donor was confirmed.

Effect of Phenolics on Hydrogen Transfer. Garry and Virk (1980) examined alcohols as possible hydrogen donors in coal liquefaction. Hydrogen transfer reactions between cyclohexanol (the donor) and anthracene and phenanthrene (the acceptors) were measured at short $(0.16 \mathrm{hr})$ and long (12 hr) reaction times reactions conditions of 300 to $425^{\circ} \mathrm{C}$. The initial donor/acceptor ratios of 0.125 to 15.4 to 1 were used. Three reaction pathways were observed: (1) bimolecular hydrogen donation between donor and acceptor; (2) reversion of the hydrogenated acceptor to the original acceptor by two mechanisms (a) hydrogen elimination and disportionation and (b) pyrolytic donor decomposition.

Hydrogen transfer reactions in coal liquefaction systems have been shown to be promoted by the presence of phenolics by Kamiya et al. (1978). In the liquefaction of coal, the presence of phenolics compounds enhanced coal liquefaction without additional hydrogen consumption in 
the presence of tetralin. The efficiency of the particular phenolic was dependent on the coal used and the phenolic concentration. The mechanisms by which the phenols promoted coal liquefaction was by accelerating scission of ether linkages. This mechanism was substantiated by use of a model system 2,2'-dinaphthyl which underwent decomposition under these conditions.

The effect of phenolic compounds on the dissolution of coal by aromatic-donating solutions has also been studied by Sato and Kamiya (1978). The effect of the acidition of phenolic compounds on the production of SRC was studied by mixing the oxygen-containing compounds with methylnaphthalene and various additives and reacting at $435^{\circ} \mathrm{C}$ for 30 minutes with 20 atm of hydrogen pressure. The phenolic compounds caused hydrogen consumption to be reduced. The coal conversions are listed in Table 3.

Table 3. Coal Conversion with Oxygen Containing Compounds

Solvent/no additive

Tetralin

Phenylcyclohexane

Phenol

2-Naphthol

Cyclohexanol

o-Cyclohexylphenol

Tetrahydro-2-naphthol

Tetralin + 2-naphthol

Tetralin + phenol

Benzophenone

Naphthoquinone

Phenylether
26.8

56.8

41

45.9

36.3

89.9

98.5

99.8

96.0

98.2

$<26.8$

$<26.8$

$<26.8$ 
Derbyshire and Whitehurst (1981) examined the behavior of hydrogen donors, polynuclear aromatics and phenolics in actual coal liquefaction systems. They found that hydrogen donors and polynuclear aromatics act synergistically where hydrogen donors reduced charring as do polynuclear aromatics to a lesser extent. Phenolics as well as other functional compounds were associated with reactions which led to char formation.

Owens (1991) evaluated the hydrogen transfer from naphthenes to aromatics, coal, resid, and coal plus resid. The reactions were performed at $430^{\circ} \mathrm{C}$ in a $\mathrm{N}_{2}$ atmosphere. The reaction of perhydropyrene (PHP) with pyrene was performed at different initial weight ratios of ANT to PHP. The reaction PHP with ANT resulted in the formation of pyrene (PYR) and dihydroanthracene (DHA). The weight percents of the products formed varied according to the initial ratio of ANT/PHP with a minimum appearing at a 2:1 weight ratio. The stoichiometric weight ratio of ANT to PHP resulted in high efficiency of hydrogen donation. Increased reaction times and high ANT/PHP ratios also yielded tetrahydroanthracene (THA).

Reactions were performed with PHP, ANT, and PYR each individually with Illinois No. 6 coal obtained from the Argonne Premium Coal Sample Bank. In a nitrogen atmosphere at $430^{\circ} \mathrm{C}$, coal conversion with PHP was $85.8 \%$ but was lower with PYR, 38.3\%, and much lower with ANT 13.4\%. Combining PHP with resid at $430^{\circ} \mathrm{C}$ in nitrogen helped to prevent retrogressive reactions; however, the combination of either PYR or ANT with resid at these conditions resulted in retrogressive reactions. Reactions of ANT with coal and ANT with resid resulted in hydrogenation of ANT yielding some production of DHA. Combining PHP with ANT or PYR with coal, resid or coal plus resid yielded higher coal and less retrogressive 
reactions of the resid. Hydrogen transfer occurred from PHP to ANT, from PHP to PYR and from PHP to coal and resid as shown by increased conversion.

Rudnick (1986a.h) has patented the process of catalyzing hydrogen transfer from naphthenes by introducing an organic sulfur compound which promoted this type of hydrogen transfer. Rudnick performed a series of reactions in which the catalysis of hydrogen transfer from different hydroaromi uc and alicyclic compounds by thiophenol was evaluated. Reactions at $440^{\circ} \mathrm{C}$ with an unspec. fied superatmospheric pressure with hydrogen-rich compounds such as decahydropyrene with herzophenone resulted in conversion to the aromatic pyrene and several less hydrogenated hydriaromatic compounds. The cycloalkane, PHP, did not react with benzophenone (BEN) at $\$ 40^{\circ} \mathrm{C}$ after one hour of reaction; however, in the presence of $0.51 \mathrm{wt}$ \% thiophenol, $94.7 \%$ diphenylmethane was formed from benzophenone.

These reactions were repeated by Wang $(1992)$ at $440^{\circ} \mathrm{C}$ in the presence and absence of thiophenol. The reactions were conducted at an initial charge of 400 and 1250 psig in both nitrogen and hydrogen. The thiophenol catalyst was introduced at $0.51 \mathrm{wt} \%$ and the PHP to BEN mole ratio was 0.42 .

The thermal and catalytic reactions in $\mathrm{N}_{2}$ produced DPM from BEN. Although more DPM was produced from BEN in the catalytic reaction, only $5 \%$ was produced. In the thermal and catalytic reactions in $\mathrm{H}_{2}$, more hydrogenation of BEN to DPM occurred than in $\mathrm{N}_{2}$. The different $\mathrm{H}_{2}$ pressures were used: 400 and 1250 psig were introduced at ambient temperature. The higher $\mathrm{H}_{2}$ pressure increased the amount of DPM formed. The highest conversion of BEN to DPM was 30 mole \%, which was produced at $440^{\circ} \mathrm{C}$ and 1250 psig $\mathrm{H}_{2}$ charged at ambient. None of the eight conditions used were able to replicate the $94 \%$ production of DPM observed 
by Rudnick (1986). Substantial incorporation of molecular $\mathrm{H}_{2}$ occurred in the reactions conducted in $\mathrm{H}_{2}$.

Hydrogen donor reactions in co-processing of coal and petroleum resids were investigated by Wang (1992) using different hydrogen-rich model compounds and reduced resids as donors and aromatics as acceptors. Three hydrogen-rich donor species were compared: cyclic olefins, hydroaromatics, and cycloalkanes; the aromatic acceptors included pyrene and anthracene; and the resids were reduced by the Birch method. Hydrogen was transferred most readily at $380^{\circ} \mathrm{C}$ by cyclic olefins, followed by hydroaromatics, and the least by cycloalkanes. Catalysis by thiophenol promoted the hydrogen transfer by the cycloalkanes at $380^{\circ} \mathrm{C}$ but had little effect at $440^{\circ} \mathrm{C}$. Reduced resids transferred substantially more hydrogen to an aromatic acceptor than did the parent resids. In a tertiary system of resid, cycloalkane, and aromatic, the reduced resids yielded more hydrogen transfer and promoted hydrogen donation from the cycloalkanes in a nitrogen atmosphere. Reduction of resids by the Birch method appeared to be an effective means of increasing the hydrogen donor ability of resids.

\section{EXPERIMENTAL WORK}

The Project Work Plan for "The Role of the Resid Solvent in Co-Processing With Finely Divided Catalysts, " was prepared after notification of NEPA approval of the contract. The Work Plan was discussed with the DOE Technical Officer, Dr. Arun Bose, who suggested several changes and additions. The changes were made to the Project Work Plan which was resubmitted to Dr. Bose in August.

Experimental work began on Task II. Mr. Jing Shen, the graduate research assistant on this contract, began performing experiments to establish reproducibility in performing gas 
chromatographic analyses. This analysis method is an essential part of the experimental work-up of the experiments to be performed in Task II. He acquired the skills of qualitative and quantitative analysis of GC samples. Quantitative analysis was performed using the internal standard method with 1 xylene as the internal standard. In the process of performing the GC reproducibility experiment, the GC capillary column shattered, which required acquiring a replacement. The new column was purchased and installed in the gas chromatograph during July. After several instrument repairs, Mr. Shen was able to attain accurate and reproducible analyses. The system that he used for testing was naphthalene, tetralin, and decalin in hexadecane. He was able to attain response factors for each of these species as well as analyze accurately samples with known amounts of naphthalene, tetralin, and decalin.

Initial reactions using tubular microreactors were performed in August. Naphthalene hydrogenation reactions were performed under thermal conditions. Material balances were obtained and the liquid products were analyzed by gas chromatography. The thermal reaction conditions of $400^{\circ} \mathrm{C}, 1250$ psig $\mathrm{H}_{2}$ at ambient conditions, and $1 \mathrm{wt} \%$ naphthalene resulted in a very small amount of tetralin and decalin (less than 3\%) being formed.

The research performed in September focused upon performing tubular microreactor studies using a naphthalene system with molybdenum naphthenate as the catalyst. The reactions were performed using typical co-processing reaction conditions of $400^{\circ} \mathrm{C}, 30$ minute reaction time, 1250 psig hydrogen pressure introduced at ambient temperature and hexadecane as the solvent. Trie molybdenum naphthenate was introduced at a level of $500 \mathrm{ppm}$. The sulfur was added in excess at a 3 to $1 \mathrm{~S}$ to Mo stoichiometric ratio, presuming that $\mathrm{MoS}_{2}$ was formed. The reactions were performed both with and without additional sulfur. The reaction products were 
analyzed by gas chromatography (Varian Model 3400) using a HT-5 capillary column and the internal standard method for quantitation. Baseline experiments using hexadecane present as the solvent only were performed in order to determine the hydrocracking products that occurred at the reaction temperature and pressure. The amount of hydrocracking that occurred was quite small being in range of several percent.

The reaction performed with naphthalene with molybdenum naphthenate without sulfur yielded no hydrogenation of naphthalene. In fact, the naphthalene was recovered unreacted just as it was in the thermal reactions. The liquid products from the molybdenum naphthenate reaction contained black precipitates that indicated that the molybdenum naphthenate decomposed during the reaction.

When sulfur was added to the naphthalene reaction using molybdenum naphthenate as the catalyst, hydrogenation of naphthalene occurred. The sulfur was added in a 3 to 1 stoichiometric ratio of $\mathrm{S}$ to $\mathrm{Mo}$ to form $\mathrm{MoS}_{2}$. The primary product of hydrogenation was tetralin with almost complete conversion of naphthalene. A trace amount of decalin was also formed. During the reaction, a black precipitate for $\mathrm{MoS}_{2}$ was formed as well as $\mathrm{H}_{2} \mathrm{~S}$ which was detected by its characteristic odor when the gases were released from the reactor. Product recoveries were good.

The only problem encountered in these experiments was temperature control of the sand bath. The primary cause was water being present in the air lines feeding the sand baths. A new water filter was ordered, received, and installed. This filter should help eliminate the problem. 


\section{FUTURE WORK}

The work planned for next quarter is to begin reactions using perhydropyrene and anthracene in thermal baseline reactions. The perhydropyrene has been ordered. Procedures are being developed to perform these reactions without using a solvent. 


\section{REFERENCES}

Bedell, M.S. and Curtis, C.W. "The Chemistry and Reactivity of Cyclic Olefins as Hydrogen Donors in Coal Liquefaction," Energy Fuels, 5 , 469, 1991.

Chiba, K.; Tagaya, H.; Saito, N. "Liquefaction of Yallourn Coal by Binary Solvent System" Energy Fuels, 1(4), 338, 1987a.

Chiba, K.; Tagaya, H.; Suzuki, T.; Suzuki, T. "Evaluation of the Hydrogen Shuttling Ability of Coal Liquefaction Solvents," Bull. Chem. Soc. Jpn., 60(7), 2669, $1987 \mathrm{~b}$.

Clarke, J. W.; Rantell, T.D.; Snape, C.E. "Reactivity of Cycloalkanes During the Solvent Extraction of Coal," Fuel, $\underline{63}(10), 1474,1984$.

Curtis, C. W.; Guin, J.A.; Jeng, J.F.; Tarrer, A.R. "Coal Solvolysis with a Series of CoalDerived Liquids," Fuel, 60, 677, 1981.

Derbyshire, F.J.; Whitehurst, D.D. "The Criticalities of Solvent Composition in Coal Liquefaction," High Temp-High Pressures, 13(2), 177, 1981.

Gagarin, S. G.; Krichko, A. A.; Galkina, A. A. "Thermodynamics of the Transfer of Hydrogen in Polynuclear Systems. Effect of Substituents," Khim Tverd. Topl, (5), 28, 1979.

Garry, J.J.; Virk, P.S. "Hydrogen Transfer from Alcohol Donors to Aromatic Substrates, " $\underline{\text { ACS }}$ Fuel Div. Preprint, 25(4), 132, 1980.

Kamiya, Y.; Sato, H.; Yao, T. "Effect of Phenolic Compounds on the Liquefaction of Coal in the Presence of Hydrogen-Donor Solvent," Sogo Shikensho Nenpo, 37, 225, 1978.

Kuhlmann, E.J.; Jung, D.Y.; Guptill, R.P.; Dyke, C.A.; Zang, H.K. "Coal Liquefaction Using A Hydrogenated Creosote Oil Solvent," Fuel , 64F(11), 1552, 1985.

Lang, I.; Varecka, P.; Parisova, J.; Machovic, V.; Spatna, V. "Oils from Coal Hydrogenation," Ropa Uhlie, 26(9), 539, 1984.

Later, D.W.; Camaioni, D.M. "Determination of Hydrogen Donating Properties of Coal Liquefaction Process Solvents," ACS Fuel Div. Preprint, 30(2), 339, 1985.

Owens, R.M., Master's Thesis, Auburn University, 1991.

Wang, S. L., Master's Thesis, Auburn University, 1992. 
Obara, T.; Yokona, T.; Sanada, Y. "Relationships Between Ifydrogen Donor Abilities and Chemical Structure of Aromatic Compounds in Terms of Coal Liquefaction," Fuel, $\underline{62}$ (7), 813, 1983.

Ouchi, K.; Makabe, M. "Hydrogen Transfer in the Hydrogenation of Model Compounds," Fuel, 67(11), 1536, 1988.

Pajak, J.; Brower, K. R. "On the Mechanism of Hydrogen Transfer from Decalin to Coal. Pressure Effect and Kinetic Isotype Effect," Energy Fuels, 1(4), 363, 1987.

Rincon, J.M.; Angulo, R. "Petroleum Heavy Oil Mixtures as a Source of Hydrogen in the Liquefaction of Cerrejon Coal," Fuel, 모, 899, 1986.

Rincon, J.M.; Cifuentes, E.; Jimenez, A. "Liquefaction of Cerrejon Coal Using Pitch as Hydrogen Donor Solvent," Rev. Colomb. Quim, Volume Date 1985 14(1-2), 59, 1987.

Rudnick, L. R.; Gudath, S. "Determination of Free Radical Concentration by ESR During Petroleum Resid Upgrading," ACS Div. Pet. Chem. Preprint., 31(3-4), 686, 1986.

Rudnick, L. R.; Mobil Oil Corp., USA, "Conversion of Alicyclic Compounds into Aromatic Compounds," Eur. Pat. Appl. EP 195541 A1, 24 Sep 1986.

Rudnick, L. R.; Mobil Oil Corp., USA, "Hydrogenation," Eur. Pat. Appl. EP 195539 A2 24 Sep 1986b.

Schulten, H. R.; Marzec, A. "Radical Hydrogenation of Coal Studies by Field Ionization Mass Spectrometry," Fuel Processing Technology, 15, 307, 1987.

Song, C., Hanaoka, K.; Ono, T.; Nomura, M. Bull. Chem. Soc. J., 61 3788-3790 (1988).

Tagaya, H.; Ando, H.; Suzuki, T.; Murakata, T.; Sato, S.; Chiba, K. "Constitution of Coal Liquefaction Solvent," Yamagata Daigaku Kiyo, Kogaku, 20(1), 51, 1988.

Tagaya, H.; Katsuma, K.; Shibazaki, Y.; Chiba, K. "Coal Liquefaction Using an IndeneNondonor Mixtures as Solvent," Fuel, 67(6), 789, 1988. 

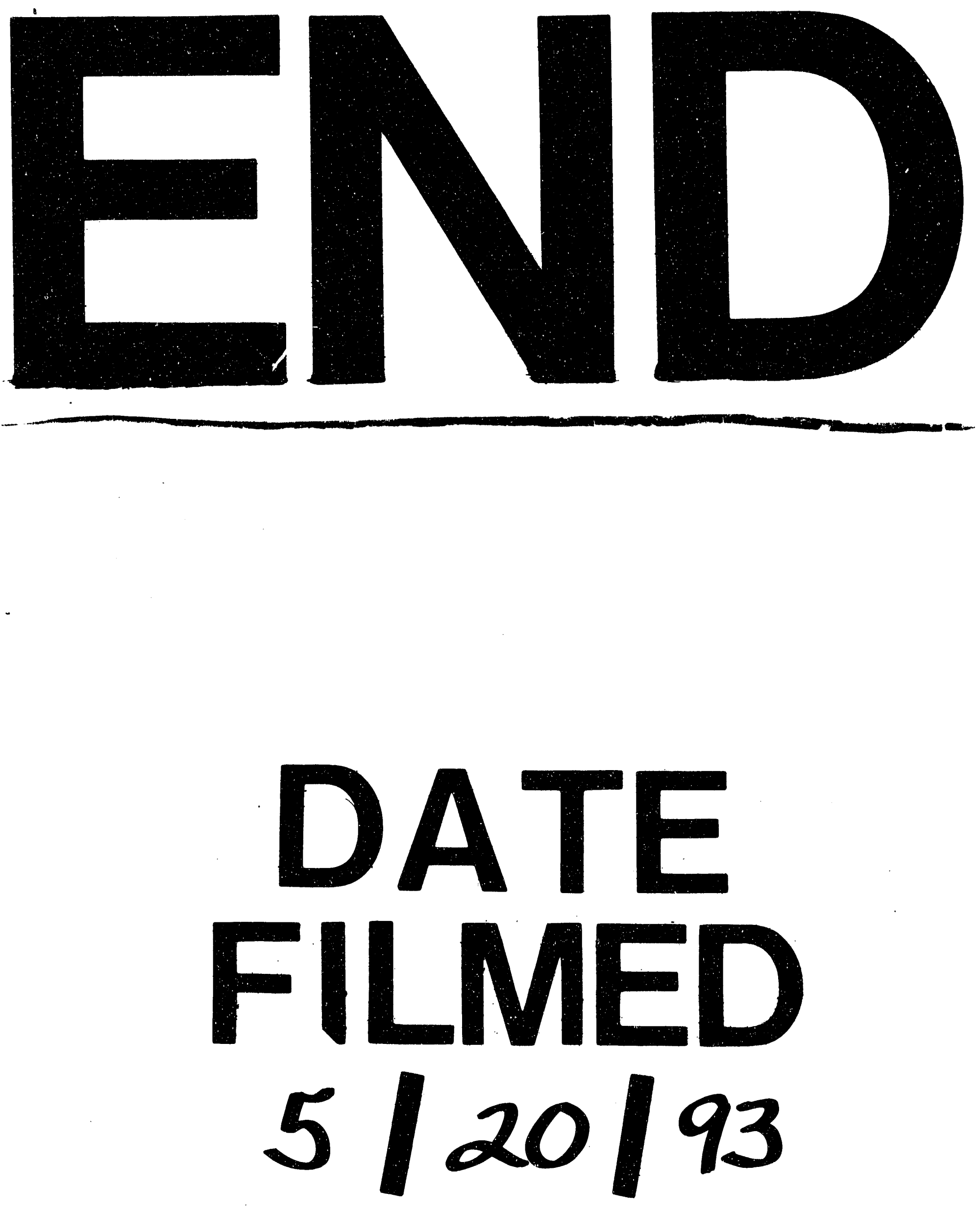
